OPEN ACCESS

Edited by: Baltasar Mayo,

Spanish National Research Counci (CSIC), Spain

Reviewed by:

Barbara Metzler-Zebeli,

University of Veterinary Medicine

Vienna, Austria

Natasa Golic,

University of Belgrade, Serbia

${ }^{*}$ Correspondence:

Elizabeth A. Rettedal

elizabeth.rettedal@agresearch.co.nz

Specialty section:

This article was submitted to

Food Microbiology,

a section of the journal

Frontiers in Microbiology

Received: 31 August 2018

Accepted: 20 February 2019

Published: 06 March 2019

Citation:

Rettedal EA, Altermann E, Roy NC and Dalziel JE (2019) The Effects of Unfermented and Fermented Cow and Sheep Milk on the Gut Microbiota. Front. Microbiol. 10:458. doi: 10.3389/fmicb.2019.00458

\section{The Effects of Unfermented and Fermented Cow and Sheep Milk on the Gut Microbiota}

\author{
Elizabeth A. Rettedal ${ }^{1,2 *}$, Eric Altermann ${ }^{1,2}$, Nicole C. Roy ${ }^{1,2,3}$ and Julie E. Dalziel1,2 \\ ${ }^{1}$ Food Nutrition \& Health Team, AgResearch (Grasslands Research Centre), Palmerston North, New Zealand, ${ }^{2}$ Riddet \\ Institute, Massey University, Palmerston North, New Zealand, ${ }^{3}$ The High-Value Nutrition National Science Challenge, \\ Palmerston North, New Zealand
}

A variety of fermented foods have been linked to improved human health, but their impacts on the gut microbiome have not been well characterized. Dairy products are one of the most popular fermented foods and are commonly consumed worldwide. One area we currently lack data on is how the process of fermentation changes the gut microbiota upon digestion. What is even less well characterized are the possible differences between cow and other mammals' milks. Our aim was to compare the impact of unfermented skim milk and fermented skim milk products (milk/yogurt) originating from two species (cow/sheep) on the gut microbiome using a rat model. Male Sprague-Dawley rats were fed a dairy-free diet supplemented with one of four treatment dairy drinks (cow milk, cow yogurt, sheep milk, sheep yogurt) for 2 weeks. The viable starter culture bacteria in the yogurts were depleted in this study to reduce their potential influence on gut bacterial communities. At the end of the study, cecal samples were collected and the bacterial community profiles determined via $16 S$ rRNA high-throughput sequencing. Fermentation status drove the composition of the bacterial communities to a greater extent than their animal origin. While overall community alpha diversity did not change among treatment groups, the abundance of a number of taxa differed. The cow milk supplemented treatment group was distinct, with a higher intragroup variability and a distinctive taxonomic composition. Collinsella aerofaciens was of particularly high abundance (9\%) for this group. Taxa such as Firmicutes and Lactobacillus were found in higher abundance in communities of rats fed with milk, while Proteobacteria, Bacteroidetes, and Parabacteroides were higher in yogurt fed rats. Collinsella was also found to be of higher abundance in both milk (vs. yogurt) and cows (vs. sheep). This research provides new insight into the effects of unfermented vs. fermented milk (yogurt) and animal origin on gut microbial composition in a healthy host. A number of differences in taxonomic abundance between treatment groups were observed. Most were associated with the effects of fermentation, but others the origin species, or in the case of cow milk, unique to the treatment group. Future studies focusing on understanding microbial metabolism and interactions, should help unravel what drives these differences.

Keywords: gut microbiome, fermentation, cow, sheep, cecal microbiota 


\section{INTRODUCTION}

The old adage "You are what you eat," now appears to accurately reflect the evidence behind the composition and function of the gut microbiome. While other factors such as genetics (Turnbaugh et al., 2009) appear to play a part, environmental factors such as diet have amassed a large amount of evidence as to their influence in building and modifying gut microbial communities (Spor et al., 2011; David et al., 2014; Bokulich et al., 2016). The microbiome has a vital and complex symbiotic relationship with their host, and a fine balance between the two appears necessary to maintain optimal health. Although there are limited studies that concretely prove a cause and effect (i.e., is it microbiota dysbiosis that causes disease or disease that shifts the microbiota), a number of health conditions, including obesity, diabetes, and inflammatory bowel disease (IBD), have been linked to shifts in the gut microbiome (Ley et al., 2005; Frank et al., 2007; Cho and Blaser, 2012). Trying to elucidate what drives and constitutes a balanced gut microbiome and how we can maintain or directionally alter it favorably, has driven research into understanding the effects of food on the gut microbiome.

Fermented foods have a long history of use in humans and have been associated with a number of health benefits (Hata et al., 1996; Kawase et al., 2000; Guyonnet et al., 2007). Consumption of fermented products has been linked to improvements in cholesterol and blood pressure levels, a reduced risk of type 2 diabetes, and reduction in gut irregularity (Chen et al., 2014; Fekete et al., 2015; Cardoso Umbelino Cavallini et al., 2016; Díaz-López et al., 2016; Laatikainen et al., 2016; Nagata et al., 2016). To produce fermented food products, live microorganisms are added to a food, and metabolic activities modify the physical and nutritional characteristics by breaking down complex components and forming by-products.

Although many studies credit the observed health benefits to the live microorganisms in fermented foods, some studies have shown beneficial effects of fermented products containing no viable microorganisms (Ouwehand and Salminen, 1998). These effects have been attributed to the interaction of non-viable bacteria directly with the immune system or the products of microbial fermentation, such as bioactive peptides (Ouwehand and Salminen, 1998). Purified versions of these peptides have been shown to have an effect on bacterial growth (Hartmann and Meisel, 2007; Erdmann et al., 2008) which could potentially modify the composition and function(s) of the gut microbiota.

Yogurt is one of the most commonly consumed fermented foods. Although cow milk is most commonly utilized, a variety of other mammalian milks are available for the commercial production of yogurt. The use of non-bovine milk products has become more popular in Western markets, as people with allergies or sensitivities to cow milk may be able to tolerate nonbovine products (El-Agamy, 2007). The milks across mammalian species also have different nutritional and flavor profiles, which may encourage their consumption.

Currently, we lack an understanding of how consuming fermented foods differs in impact on the gut microbiome from their unfermented forms. Fermentation is known to alter nutritional availability and bioactive compounds, including bioactive peptides, which might be expected to impact the microbiota (Azuma et al., 1984; Liepke et al., 2002). There is also some debate on the extent that fermented foods are capable of affecting gut microbial communities (Veiga et al., 2010, 2014; McNulty et al., 2011). As composition of milk constituents differs among mammals, differences in their effect on the microbiota and pre- and post-fermentation may also occur.

Our aim was to characterize the effects of unfermented and fermented milk (yogurt) originating from cow and sheep on the composition of the gut microbiota. We hypothesized that we would observe differences in bacterial communities due to fermentation, but animal origin would more robustly influence those differences. Rats were fed a solid dairyfree diet supplemented with one of four dairy treatments for 2 weeks. Their cecal bacterial communities were then characterized by looking at diversity, community composition, and correlations with metadata.

\section{MATERIALS AND METHODS}

The rats used in this study were part of another experiment (parallel) that examined the effect of these dairy treatments on transit time and characterized their peptide profiles and potential bioactivity (Dalziel et al., 2018). Here we separately assessed the cecal contents following the completion of that study. The methods regarding the animal study and dairy drinks are described in Dalziel et al. (2018) but reiterated here for clarity.

\section{Dairy Drinks Treatments}

Cow skim milk powder [SMP 001 (111115)] (38\% protein, $<0.1 \%$ fat, $45 \%$ lactose) was donated by NZ Food Innovation Ltd. (Hamilton, New Zealand) while sheep skim milk powder (031215 Cipher number KY03) (52\% protein, $1 \%$ fat, 37\% lactose) was contributed by Blue River Dairy (Invercargill, New Zealand). Powdered milk rather than fresh was used due to the variable availability of large quantities of fresh skimmed sheep milk and for nutrient batch consistency. The $\mathrm{pH}$ of the reconstituted cow and sheep milk was measured and found to be $6.5 \pm 0.1$ for both species. To produce the yogurt, the cow $(140 \mathrm{~g} / \mathrm{L})$ and sheep $(105 \mathrm{~g} / \mathrm{L})$ skim milk powders were rehydrated in water using a stick blender for $2 \mathrm{~h}$. Each milk was then slowly heated to $85^{\circ} \mathrm{C}$ over $2 \mathrm{~h}$ and held at that temperature for $30 \mathrm{~min}$, while under constant stirring. The milks were then cooled to $43^{\circ} \mathrm{C}$ and a starter culture mix $(0.26 \mathrm{U} / \mathrm{L})$ of Streptococcus thermophilus and Lactobacillus delbrueckii ssp. bulgaricus (CHR Hansen YFL811 - YoFlex ${ }^{\circledR}$ ) was added. This starter culture was chosen for its reliability in producing a consistent product as a drinkable yogurt. Inoculated milks were incubated at $43^{\circ} \mathrm{C}$ until the $\mathrm{pH}$ dropped to 4.5 ( 4 to $5 \mathrm{~h}$ ). The yogurts were then frozen at $-20^{\circ} \mathrm{C}$ in shallow trays. To reduce bacterial viability and improve freeze-drying, the yogurts were annealed by thawing to $-5^{\circ} \mathrm{C}$ and refreezing at $-20^{\circ} \mathrm{C}$ before freeze-drying.

The dairy drinks were prepared for usage by reconstituting the milk or yogurt powder to a $3 \%$ protein concentration in water and blending for $30 \mathrm{~s}$. Drinks were made up daily and provided as two feeds with half kept at $4^{\circ} \mathrm{C}$ before use in the animal experiment. 
A $3 \%$ protein concentration was chosen so the yogurt could be delivered as a free-flowing drinkable substance.

To determine the bacterial viability of $S$. thermophilus and L. delbrueckii ssp. bulgaricus in dairy drinks, milks and yogurts were resuspended in water at $3 \%$ protein by blending (30 s). Serial dilutions were performed in phosphate buffered saline (PBS) and $100 \mu \mathrm{L}$ spread on selective agar plates in triplicate. S. thermophilus was grown at $37^{\circ} \mathrm{C}$ for $24-48 \mathrm{~h}$ on Mitis Salivarius agar under $5 \% \mathrm{CO}_{2}$ conditions. L. delbrueckii ssp. bulgaricus was grown at $45^{\circ} \mathrm{C}$ for $72 \mathrm{~h}$ on MRS agar ( $\mathrm{pH}$ 5.2) (Fort Richard Laboratories Ltd, Auckland, New Zealand) under anaerobic conditions. L. delbrueckii ssp. bulgaricus was not detected in any milk or yogurt samples. S. thermophilus was recovered for the cow yogurt $\left(4.5 \times 10^{6} \mathrm{CFU} / \mathrm{mL}\right)$ and sheep yogurt $\left(1.5 \times 10^{4} \mathrm{CFU} / \mathrm{mL}\right)$, but not recovered from the milks.

\section{Animal Care and Study Design}

The animal study was approved by the AgResearch Grasslands Animal Ethics Committee (Palmerston North, New Zealand) (AE13501) in compliance with the Animal Welfare Act (1999, New Zealand). Forty male Sprague-Dawley rats (initial weight $404 \pm 27 \mathrm{~g}$ ), were obtained from the AgResearch Small Animal Breeding Unit (Hamilton, New Zealand). The rats were individually housed at a constant $21^{\circ} \mathrm{C}$ with a $12 / 12 \mathrm{~h}$ light/dark cycle. Starting from 10 weeks of age, the rats were fed a dairy-free solid AIN-93M OpenSource Rodent Diet (Research Diets Inc., New Brunswick, NJ, United States) with an egg white protein source. The composition of the rat solid diet is provided in Supplementary Table S1. At 12 weeks of age, one of four dairy drinks [CM, cow milk; CY, cow yogurt; SM, sheep milk; SY, sheep yogurt] were provided ad libitum for 14 days (10 rats per group). General health score, weight, and dietary intake were recorded three times a week. Following the completion of the study, the rats were euthanized via $\mathrm{CO}_{2}$ overdose inhalation and cervical dislocation. Cecal samples were aseptically collected from rats and immediately stored at $-80^{\circ} \mathrm{C}$.

\section{Microbiota Sequencing and Analysis}

DNA was extracted from cecal samples that were thawed on ice using the Macherey Nagel Nucleospin Soil kit following the manufacturer's instructions with the addition of a $5 \mathrm{~min}$ bead-beating step $(0.6-0.8 \mathrm{~mm}$ ceramic beads, FastPrep 120). A NanoDrop ${ }^{\text {TM }}$ (Thermo Fisher Scientific) was used to quantify the DNA. DNA samples were then submitted to Omega Bioservices (Norcross, GA, United States) for library preparation and high-throughput sequencing. The libraries were prepared using the Illumina 16S Metagenomic Sequencing kit (Illumina, Inc., San Diego, CA, United States) according to the manufacturer's protocol. The V3-V4 region of the bacterial 16S rRNA gene was amplified using the 16S Amplicon PCR Forward Primer (5'-TCGTCGGCAGCGTCAGATGTGTAT AAGAGACAGCCTACGGGNGGCWGCAG) and 16S Amplicon PCR Reverse Primer (5'-GTCTCGTGGGCTCGGAGATGTGTAT AAGAGACAGGACTACHVGGGTATCTAATCC). Amplicon PCR was performed to amplify template out of input DNA samples. Briefly, each $25 \mu \mathrm{L}$ of polymerase chain reaction (PCR) reaction contained $12.5 \mathrm{ng}$ of sample DNA as input, $12.5 \mu \mathrm{L} 2 \times$
KAPA HiFi HotStart ReadyMix (Kapa Biosystems, Wilmington, MA, United States) and $5 \mu \mathrm{L}$ of $1 \mu \mathrm{M}$ of each primer. PCR reactions were carried out using the following protocol: an initial denaturation step performed at $95^{\circ} \mathrm{C}$ for $3 \mathrm{~min}$ followed by 25 cycles of denaturation $\left(95^{\circ} \mathrm{C}, 30 \mathrm{~s}\right)$, annealing $\left(55^{\circ} \mathrm{C}\right.$, $30 \mathrm{~s})$, extension $\left(72^{\circ} \mathrm{C}, 30 \mathrm{~s}\right)$, and a final elongation of $5 \mathrm{~min}$ at $72^{\circ} \mathrm{C}$. PCR products were purified using Mag-Bind RxnPure Plus magnetic beads (Omega Bio-tek, Inc., Norcross, GA, United States). A second index PCR amplification, used to incorporate barcodes and sequencing adapters into the final PCR product, was performed in $25 \mu \mathrm{L}$ reactions, using the same master mix conditions as described above. Cycling conditions were as follows: $95^{\circ} \mathrm{C}$ for $3 \mathrm{~min}$, followed by eight cycles of $95^{\circ} \mathrm{C}$ for $30 \mathrm{~s}, 55^{\circ} \mathrm{C}$ for $30 \mathrm{~s}$, and $72^{\circ} \mathrm{C}$ for $30 \mathrm{~s}$. A final $5 \mathrm{~min}$ elongation step was performed at $72^{\circ} \mathrm{C}$. The libraries were normalized with the Mag-Bind ${ }^{\circledR}$ EquiPure Library Normalization Kit (Omega Bio-tek, Inc., Norcross, GA, United States) then pooled. The pooled library $\sim 600$ bases in size was checked using an Agilent 2200 TapeStation and sequenced $(2 \times 300$ bp paired-end read setting) on a MiSeq (Illumina, San Diego, CA, United States).

The sequence data was analyzed using mothur following the methods of Schloss et al. (2009, 2011). Briefly, pairedend reads $(3,519,095$ pre-quality control paired reads) were assembled and underwent quality control that removed reads containing uncalled bases and homopolymers of greater than eight. The average quality scores across all bases was greater than 30 and the average sequence length was $416 \mathrm{bp}$. Sequences were then aligned against the SILVA database (release 132) (Quast et al., 2013). Following sequencing alignment and filtering, the sequencing reads underwent a pre-clustering step (4 bp) designed to denoise and reduce the effect of sequencing errors. Chimeric sequences were detected and removed using VSEARCH (Rognes et al., 2016). Following taxonomic classification, non-bacterial sequences were removed from the analysis and sequences were clustered into OTUs at a $97 \%$ cutoff. A total of 1,434,251 reads remained following all quality control and filtering steps with an average of 29,880 reads per sample. The number of sequences per sample was subsampled to 17,323 to equalize the number of reads across samples for all downstream analyses. BIOM tables were exported from mothur for use in other analysis programs. Raw output from mothur taxonomic classifications is available in Supplementary Table S2.

Alpha-diversity was calculated using the Shannon index. Taxonomic graphs were generated using classifications from mothur. LEfSe was used to identify taxonomic features significantly different $(p<0.05)$ and most likely to explain the differences in bacterial communities (LDA $\geq 2$ ) (Segata et al., 2011). An OTU most likely species identity was determined by a BLAST nr search (Altschul et al., 1990), utilizing the top hit. Bar chart graphics for taxonomic graphs and LEfSe results were generated using Microsoft Excel ${ }^{\circledR}$. Multiple linear regression analyses were performed using Calypso (Zakrzewski et al., 2017) to determine bacterial OTUs that correlated with previously collected intestinal transit scores (Dalziel et al., 2018). Rats with transit scores of less than 10 (6 rats) were removed from the analysis (2 CY, $2 \mathrm{SM}, 2 \mathrm{SY}$ ), as it has been previously shown 
that $\sim 10 \%$ of animals can have significantly delayed stomach emptying resulting in unusable transit data (Dalziel et al., 2016).

\section{Statistical Analyses}

Comparisons between rat dietary intake values and weights were analyzed using a one-way ANOVA. Standard deviations (SD) were also calculated and reported for average intake and body weight increases. PERMANOVA and PERMDISP analyses were perform with Calypso. $P$ values less than 0.05 were considered significant.

\section{RESULTS}

\section{Rat Dietary Intake and Weights}

Rats in this study were fed a solid dairy-free diet to remove the potentially confounding effects of other dairy components in the diet. Powdered skimmed milks were used and the dairy drinks were diluted to $3 \%$ protein to level the fat and protein intake.

Rats across all treatment groups had an average daily intake of $27 \pm 3.5 \mathrm{~g}$ (SD) of solid food and body weight increased by $19 \pm 3.9 \%$ (SD) over 14 days (Supplementary Table S3) (Dalziel et al., 2018). There was no significant difference between daily solid food intake or treatment group weights on Day 0 or 14 (Supplementary Table S3). For the dairy drinks, the CM group $(87.48 \mathrm{~mL})$ had the lowest daily mean intake and the CY group the highest $(103.73 \mathrm{~mL})$, but the intake difference between all groups was not statistically significant (ANOVA, $p=0.07$ ) (Supplementary Table S3).

\section{Cecal Microbiota Differs Among Dairy Drink Treatments}

To determine if there were differences among the four dairy drink treatment groups, the high-throughput sequencing data was analyzed for diversity, community composition, taxonomy, and correlations with metadata. To look at alpha diversity, the Shannon indices were determined. We found no significant differences between the treatment groups (Supplementary Figure S1).

Next, we determined differences in overall bacterial community composition. A Bray-Curtis principal component analysis (PCA) plot did not show a distinct separation between treatment groups, but rather more of a gradient-like distribution with the cow milk treatment showing the largest spread between individual rats (Figure 1). To determine if there might be a significant difference between groups, PERMANOVA was performed, which suggested a difference between the treatment groups $(p<0.001)$. To look at the possible effects of intragroup variation, PERMDISP was performed which indicated a significant difference $(f=4.6861, p=0.0063)$. The combined results from the PERMANOVA and PERMDISP analyses indicate that while there was a difference between treatment groups, at least some of those differences were due to variance in intragroup variability.

The taxonomic composition of the treatment groups on phylum and family levels are visualized in Figure 2. At phylum level (Figure 2A), the cow milk (CM) group was particularly distinct with increased Actinobacteria and decreased Bacteroidetes. The milks (CM, SM) had similar amounts of Firmicutes while the yogurts (CY, SY) contained comparable ratios of both Firmicutes and Bacteroidetes. At a family-level taxonomic classification (Figure 2B), taxonomic abundance differences could also be seen in specific treatments (e.g., higher Coriobacteriaceae in $\mathrm{CM}$ ) and between unfermented and fermented products (e.g., higher Lactobacillaceae in milks). The difference in community intragroup variation noted by PERMDISP analysis, suggested higher taxonomic variability among individual rats in some treatment groups (e.g., CM) (less uniform taxonomic composition). Taxonomic graphs of individual rats highlight these samples (Supplementary Figure S2).

In order to identify robust and meaningful differences in taxonomic abundances between treatment groups, we chose to use LEfSe to identify taxonomic groups with significant differences ranging from phylum to OTU. LEfSe identified 16 taxa with significant changes (Figure 3). While a number of taxa were identified, similar to the taxonomic composition graphs, the CM dairy drink treatment clearly had a more unique taxonomic representation. Its particularly high abundance in Collinsella aerofaciens (OTU6) (Collinsella, Coriobacteriaceae, Coriobacteriales, Coriobacteriia, Actinobacteria) and lower abundance in Acidaminococcaceae (Selenomonadales, Negativicutes) were absent from the other dairy drink groups.

\section{Fermentation Status Influences Cecal Microbial Communities}

The treatment-specific analysis identified that fermentation status (milk vs. yogurt) appeared to influence the composition of the microbial communities. With this in mind, we decided to use LEfSe to compare the combined milk (CM + SM) to the combined yogurt (CY $+\mathrm{SY}$ ) bacterial communities (Figure 4). Fifteen of the sixteen taxa identified in the comparison of the four treatments, also were significant in the milk vs. yogurt comparison. An additional 12 taxa were also identified as significantly different. Despite attempts to deplete the starter culture bacteria from the yogurts, some viable Streptococcus thermophilus (CY: $4.5 \times 10^{6} \mathrm{CFU} / \mathrm{mL}$, SY: $1.5 \times 10^{4} \mathrm{CFU} / \mathrm{mL}$ ) were introduced into the rats. These counts are multiple logs lower than the commonly observed abundances in commercial yogurts $\left(10^{8}-10^{9} \mathrm{CFU} / \mathrm{mL}\right)$ (Ibrahim and Carr, 2006), however, the viable number of $S$. thermophilus introduced into the rats may have been greater than the initial plate counts as the yogurts sat at room temperature for several hours during the feeding. Thus unsurprisingly, S. thermophilus (OTU27) was found in higher abundances in the yogurt, while it was nearly undetectable in the milk samples. Interestingly, Lactobacillus, including Lactobacillus murinus, was found to be higher in the milks possibly due a greater substrate availability which may have been depleted during fermentation. While Collinsella was still found in a higher overall abundance in milk, C. aerofaciens (OTU6) was not significantly different in the fermentation status comparison. The genera Phascolarctobacterium, Desulfovibrio, and Parabacteroides 

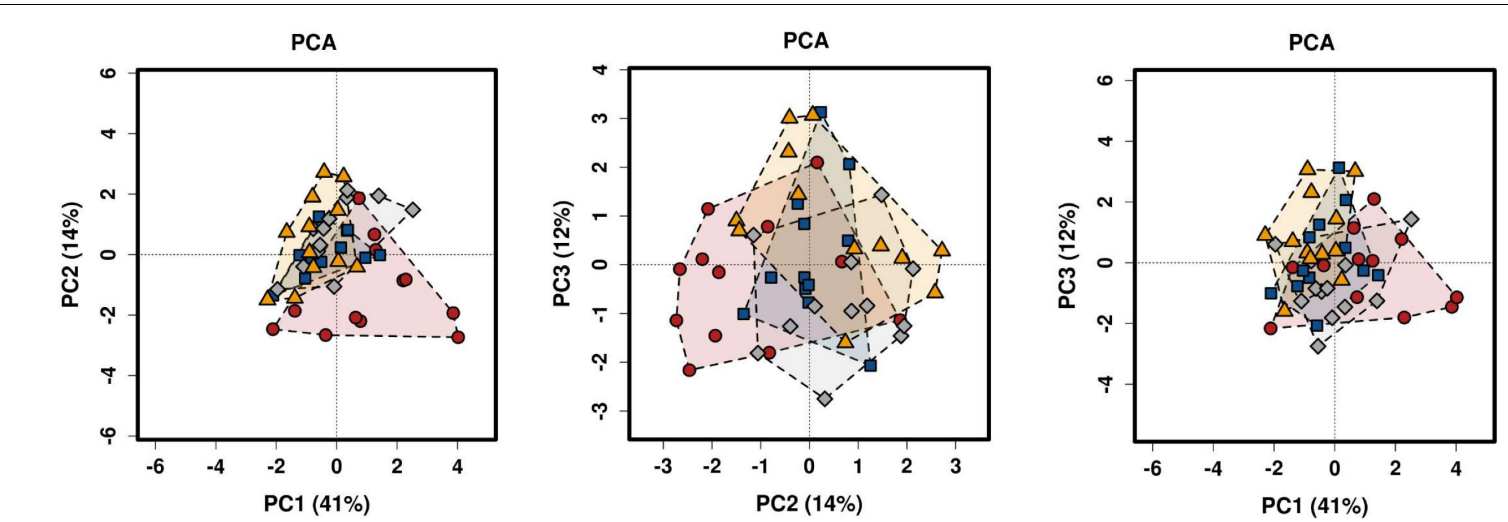

FIGURE 1 | A PCA plot of the differences in bacterial community composition between the four dairy drink treatment groups [CM, cow milk; CY, cow yogurt; SM, sheep milk; SY, sheep yogurt] as calculated using the Bray-Curtis index. The analysis was based on OTU-level taxonomic data.

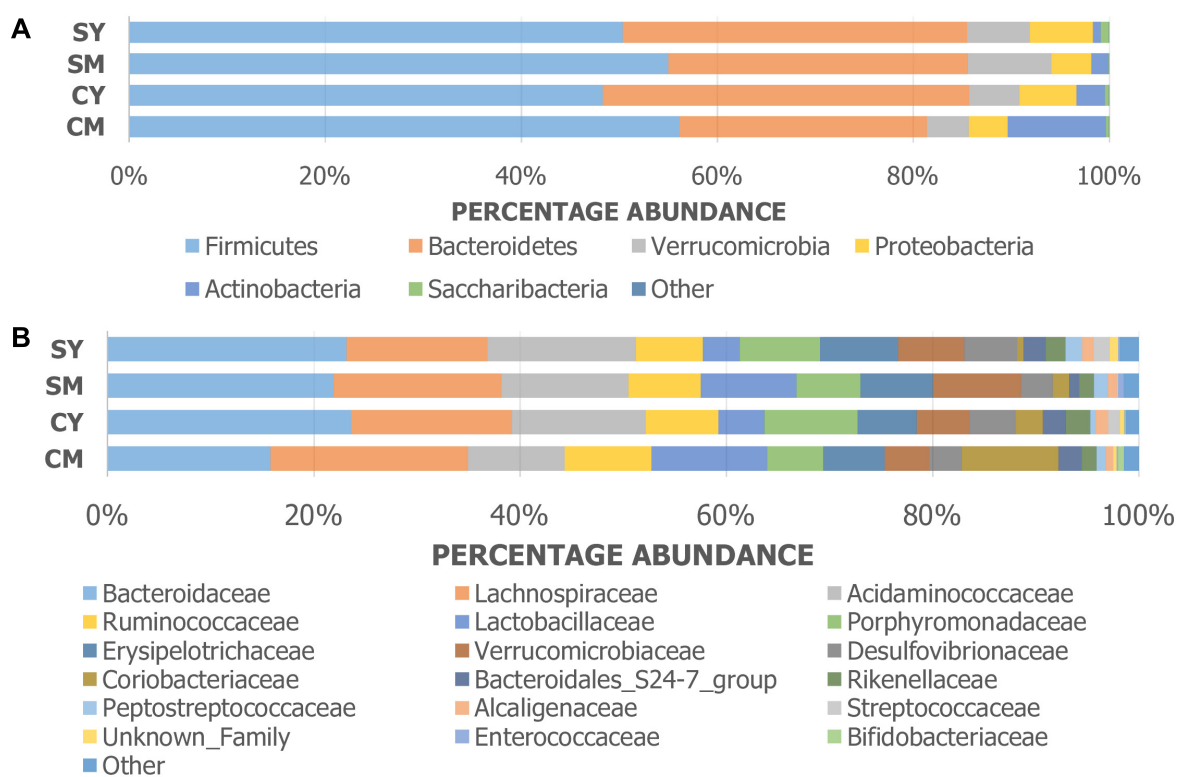

FIGURE 2 | Taxonomic graphs representing the (A) phylum and (B) family level bacterial communities (group average) found in each dairy drink treatment group [CM, cow milk; CY, cow yogurt; SM, sheep milk; SY, sheep yogurt].

were more abundant in yogurt. At a higher phylum taxonomic level, we noted a decrease in the Firmicutes:Bacteroidetes ratio in the yogurt along with an increase in Proteobacteria and decrease in Actinobacteria.

\section{Product Species Origin Has Little Effect on Cecal Microbial Communities}

Since fermentation status appeared to influence the cecal bacterial community composition, we also decided to test if species origin (cow vs. sheep) might affect the bacterial communities using LEfSe (Figure 5). While six taxa were identified as significantly different, the majority of the shift could be linked to a single OTU (C. aerofaciens, OTU6) suggesting a lesser influence of species origin on the overall bacterial community. This taxon was also identified in the treatment analyses and the genus Collinsella in the fermentation status analysis, suggesting multiple factors affect its abundance.

\section{Transit Times Do Not Strongly Correlate With Bacterial Taxa Abundance}

A parallel study run on the same rats, measured gut transit to determine if the different dairy products affected transit times. It was reported that transit was altered due to treatment method. Those effects appeared to be more related to the origin of the product (cow vs. sheep), than whether they were fermented or not (Dalziel et al., 2018). To determine whether the observed changes in transit scores could be linked to the bacterial communities, we performed regression analysis on the top 100 OTUs, utilizing the combined samples for greater statistical power. Only a single weak significant negative correlation was 


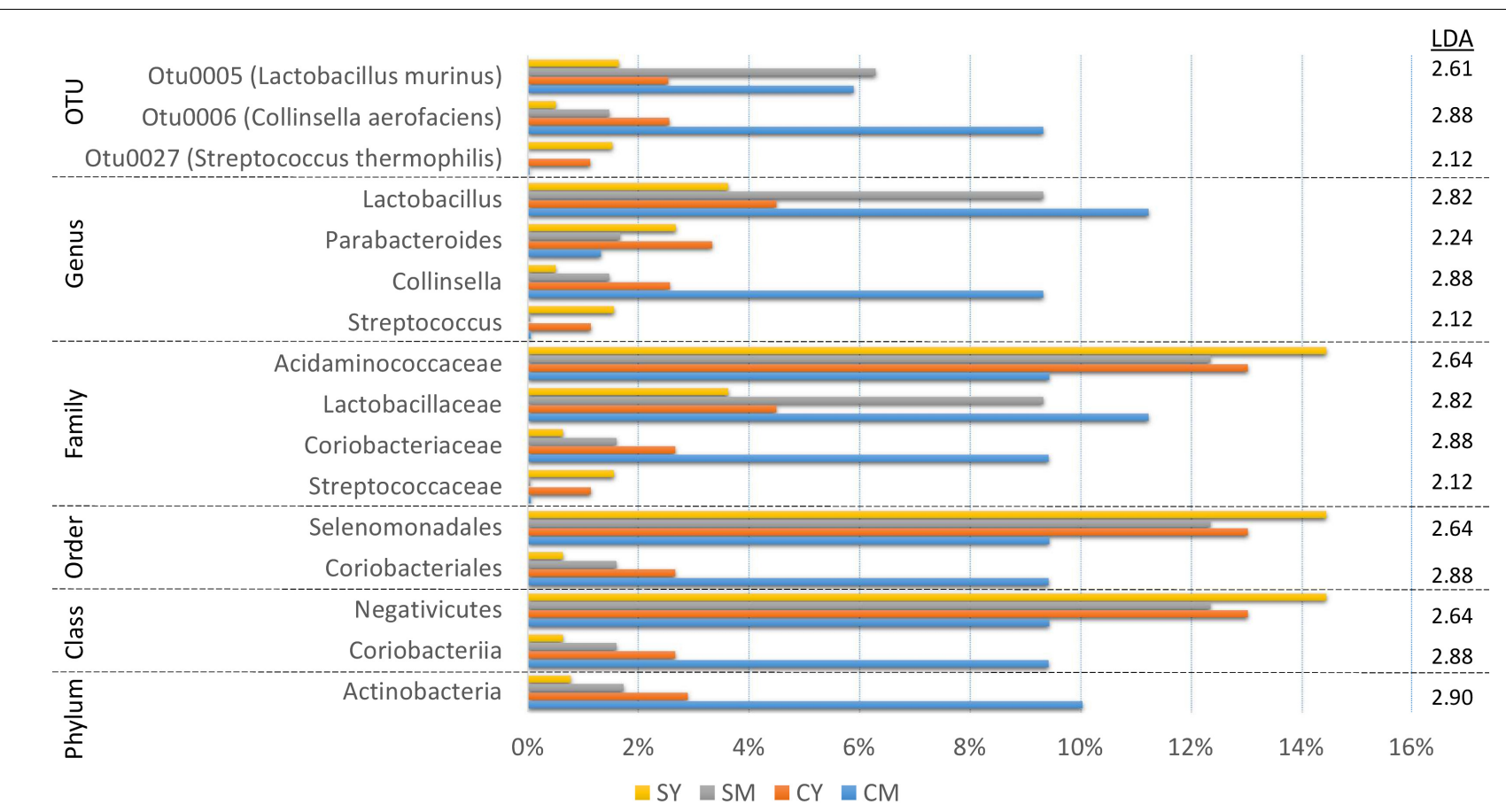

FIGURE 3 | A bar graph of the taxonomic groups indicated by LEfSe analysis to be the most likely to explain the differences between the four dairy drink treatment groups [CM, cow milk; CY, cow yogurt; SM, sheep milk; SY, sheep yogurt] $(p<0.05$, LDA score $\geq 2$ ). The bars represent the abundance of the taxa found in each treatment group. The LDA scores are listed on the right.

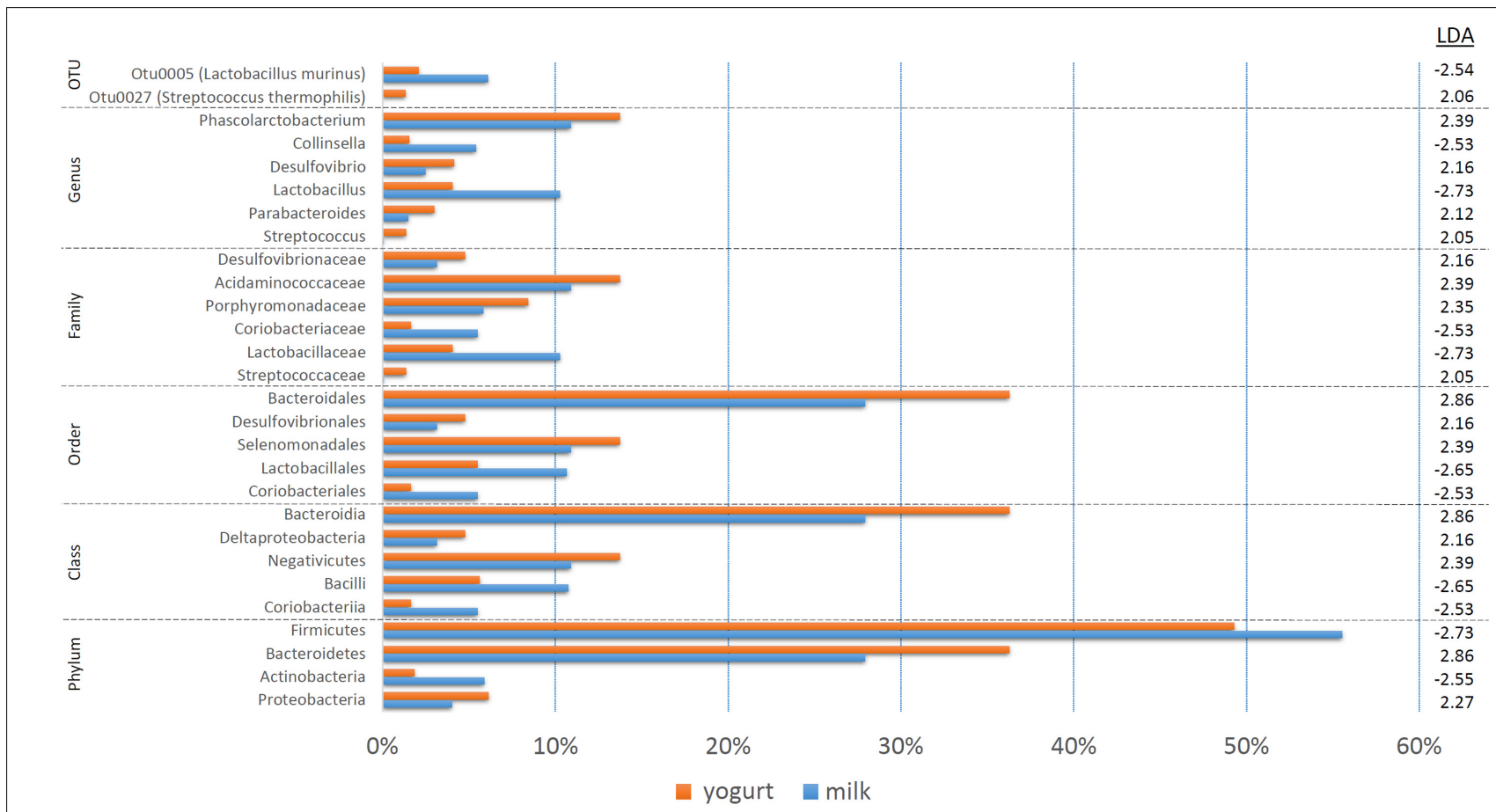

FIGURE 4 | A bar graph of the taxonomic groups indicated by LEfSe analysis to be the most likely to explain the differences between the product types (milk vs. yogurt) $(p<0.05$, LDA score $\geq 2)$. The bars represent the abundance of the taxa found in each group. The LDA scores are listed on the right. 


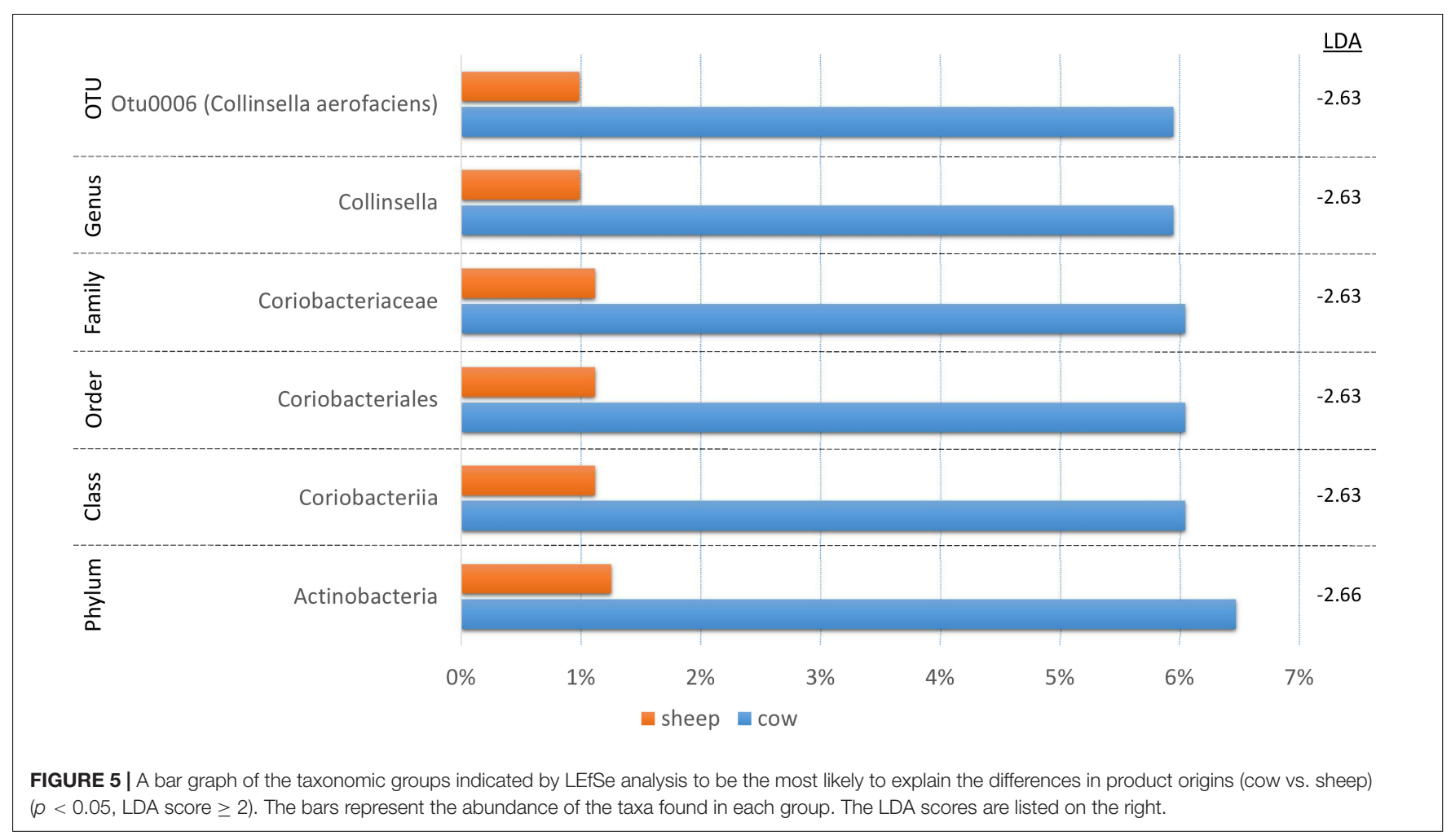

discovered ( $r=-0.3722, p=0.015)$ between Ruminococcaceae UCG-014 (OTU17) (mean abundance $=1.5 \%$ ) and total transit score, suggesting abundance of specific taxa was not strongly associated with gut transit (Supplementary Figure S3).

\section{DISCUSSION}

Here we report novel findings of the impact of unfermented and fermented milk (yogurt) from cows and sheep on the rat cecal bacterial composition. The use of healthy rodent models in our study allowed us to control both dietary and environmental factors that would be difficult to implement in human studies and removes confounding factors that make data interpretation more difficult. We showed that the effects of fermentation appeared to have a moderate influence on the composition on the gut microbiota, while animal species origin of the drinks had a small impact. This is in contrast to the parallel gut transit study in which dairy species origin was the dominant influence (Dalziel et al., 2018).

While consumption of fermented milk products containing active bacterial cultures has frequently shown increased recovery of those bacteria within the gut microbiota (Mater et al., 2005; Elli et al., 2006; Oozeer et al., 2006), any effects on the rest of the gut microbiota are less well characterized. Few studies have looked at the effects of fermented milks on the gut microbiota in healthy individuals, and particularly absent are comparisons between unfermented and fermented products. We observed differences in bacterial community composition between consumption of milk and yogurt that could be linked to both the fermentation starter culture (S. thermophilis) and other gut community members. Although the viable bacteria in the yogurt starter culture were heavily depleted or eliminated, non-viable/dead cells still may have influenced the composition of the gut microbiota. In contrast, a study in healthy human twins consuming fermented cow milk showed no detectable effect on bacterial community composition (McNulty et al., 2011), although the number of reads per sample was small $(1,640$ reads), suggesting a lack of depth to detect differences. Other investigations in healthy humans have reported similar results for yogurt (Filteau et al., 2013).

Studies that have compared the effects of both fermented and unfermented milks have been done in both humans and rodents, but they have used patients or rodent models that have or mimic gut dysfunction such as irritable bowel syndrome (IBS) or IBD (Veiga et al., 2010, 2014; Rooks et al., 2014). Rodent studies comparing fermented and unfermented cow milk treatments identified increases in Desulfovibrio and Proteobacteria in fermented milk-treated mice and increases in Lactobacillus in the unfermented milk-treated mice that match with results observed in our study (Veiga et al., 2010; Rooks et al., 2014). While increases in Proteobacteria and Desulfovibrio have been observed in several disease states vs. healthy subjects, we cannot yet discern if and what taxonomic load might represent or lead to a disease status (Gibson et al., 1991; Rowan et al., 2010; Shin et al., 2015). Most Lactobacillus are generally thought to be commensal or indicative of a healthy gut microbiota (Fijan, 2014). We did not observe an increase in Anaerostipes and Eubacterium or decrease in Enterobacteriaceae in the fermented milk as compared to unfermented milk. A human study identified 
an increase in Roseburia inulinivorans in a fermented milk treatment compared to the unfermented milk treatment gut bacterial communities (Veiga et al., 2014). Butyrate producers, such as $R$. inulinivorans, may play an important role in preventing GI disorders such as Crohn's disease (Takahashi et al., 2016).

In our study, we also observed an increase in Phascolarctobacterium and Parabacteroides in the yogurts. At a higher phylum taxonomic level, we saw a decrease in the Firmicutes:Bacteroidetes ratio in the yogurts along with a decrease in Actinobacteria. Phascolarctobacterium has been correlated with positive mood so may play a role in the gutbrain axis ( $\mathrm{Li}$ et al., 2016). Phascolarctobacterium is also a known producer of short-chain fatty acids, including butyrate (Lecomte et al., 2015), so it may mirror some of metabolic effects induced by the increase in $R$. inulinivorans observed in the previously mentioned study (Veiga et al., 2014). A decrease in the Firmicutes:Bacteriodetes ratio has previously been associated with a decrease in body mass index (BMI) (Ley et al., 2006; Turnbaugh et al., 2009). It is unsurprising to note differences in the results between our study and others, as differences in methodology (e.g., diseased vs. healthy host, mice vs. rats vs. human host, fecal vs. cecal samples, $16 \mathrm{~S}$ vs. shotgun sequencing) substantially influence the outcome. Another factor that may have influenced the results, is that powdered milks were utilized in this study while raw or pasteurized fresh milk have been studied previously.

The fecal microbiota has previously been shown to differ between rats fed cow and other mammals' milks (e.g., yaks, camels) (Wen et al., 2017). Our analysis also indicated differences in taxonomic abundances between cow and sheep milk, but overall the effects of milk origin were less pronounced than fermentation. The cow milk treatment group was distinct, as it exhibited treatment-specific effects not seen in the other groups. It also showed the greatest intragroup variability which indicates that cow milk may cause more variable gut microbial communities. This suggests particular substrates present in cow milk may trigger a non-uniform response on bacterial communities. Since these effects were not noted in the cow yogurt treatment, fermentation seemingly removes this result. It also appears to be animal species specific, as it was not seen in either sheep treatment group. To help further illustrate the variability in the cow milk treatment group, a pair-wise MorisitaHorn dissimilarity index matrix was generated in mothur (Supplementary Figure S4). Variability (e.g., SM44), was also observed in other treatment groups but was limited as compared to the cow milk treatment samples (Supplementary Figure S4). The high intragroup variability among cow milk samples, also led us to reconfirm the LEfSe results by removing the extreme outliers and performing a one-way ANOVA $(p<0.05)$ on the bacterial abundances (e.g., Collinsella, Acidaminococcaceae). The differences remained significant with or without the outliers.

Bacteria of particular interest from this research included Collinsella and Lactobacillus. The abundance of Collinsella appeared to be influenced by both fermentation (milk vs. yogurt) and species origin (cow vs. sheep) and was found in higher abundance in milk (as compared to yogurt from same animal species), particularly cow milk. Collinsella aerofaciens, generally considered a gut commensal, is commonly found in the human intestine (Rajilić-Stojanović and de Vos, 2014). Increased Collinsella abundance has been associated with both positive and negative health conditions (Malinen et al., 2010; Joossens et al., 2011; Lambeth et al., 2015; Chen et al., 2016), but there is really no consensus of its health effects. Further study is needed as it is not well characterized and has been reported in very low abundance, including those linked to health outcomes. C. aerofaciens is known to be able to ferment a range of different carbohydrates, including starches (Kageyama et al., 1999), and there is evidence that it plays a major role in gut lactose fermentation (Kovatcheva-Datchary, 2010). Studies have linked the use of fructooligosaccharides (FOS) and galactooligosaccharides (GOS) to increased activity (Tannock et al., 2004) or abundance (Dewulf et al., 2013; Azcarate-Peril et al., 2017). In a 15 member human gut model in gnotobiotic mice, C. aerofaciens was reduced after addition of fermented milk bacterial strains, possibly due to competition with lactic acid bacteria (McNulty et al., 2011).

Lactobacilli are capable of metabolizing a wide range of oligosaccharides and some are considered probiotic (Gänzle and Follador, 2012). Lactobacillus sp. have been linked to a number of beneficial effects including improvement in depression symptoms and gut function (Verna and Lucak, 2010; Wallace and Milev, 2017). Although lactic acid bacteria such as Lactobacillus are often associated with yogurt (Adolfsson et al., 2004), this may be due to their delivery as live fermentation starter cultures rather than actual growth stimulation of lactobacilli in vivo. We found increased abundances of Lactobacillus in both cow and sheep milk treatments as compared to their yogurt counterparts which may have been influenced by differences in substrate availability. Lactose can decrease more than $50 \%$ post-fermentation (yogurt vs. milk) (Alm, 1982) and the milks used in this study also differed in lactose concentrations (cow milk 3.6\%, sheep milk $2.2 \%$ ). The by-products of lactose fermentation (e.g., lactic acid, ethanol) in yogurt by beta-galactosidases, may be linked to our observed increase in Desulfovibrio which can use lactate as an electron acceptor (Price et al., 2014). In this study, there appears to be additional factors at play since changes in abundance of Collinsella, another lactose utilizer, do not parallel Lactobacillus. Lactic acid bacteria in starter cultures also utilize proteolysis to help successfully drive the fermentation process (Savijoki et al., 2006). This has downstream effects on the availability of types of substrates in fermented products, such as peptides, which could influence microbial abundances (Raveschot et al., 2018).

Bacterial strains exhibit individual preferences for nutrients that affect their ability to compete for specific resources (Fischbach and Sonnenburg, 2011). Both milk species origin and fermentation status influence the availability of nutrients and bioactive compounds in milk products (Pessione and Cirrincione, 2016; Balthazar et al., 2017). Raw sheep milk has a greater amount of protein, fat, and total energy compared to cow (Balthazar et al., 2017). The concentration of vitamins, minerals, and lactose concentrations can vary between animal species (Balthazar et al., 2017). In this study, the use of skim milks reduced the influence of absolute fat. While the milks used 
in this study were also balanced for protein concentration, the types of proteins in cow and sheep milk still differ and may have influenced the composition of the cecal microbiota.

While lactose is the only major carbohydrate found in cow and sheep milk, the concentrations of the different types of protein fractions varies greatly. There is roughly an 80:20 ratio of total casein and whey proteins in both species, but sheep milk contains mostly $\beta$-casein $(\sim 62 \%)$ while cow milk has $50 \% \alpha$-casein $(40 \%$ being $\alpha$ S1-casein) (Balthazar et al., 2017). Cow milk only contains half the $\beta$-casein of sheep but $6 \times$ more $\alpha S 1$-casein. Specific types of casein have been previously shown to stimulate growth or particular functions, such as biofilm formation, in certain lactic acid bacteria (Azuma et al., 1984; Smid et al., 1991; Varhimo et al., 2011). Amino acid composition also varies among protein fractions types (e.g., $\alpha / \beta$-casein, whey) and by animal origin (Gordon et al., 1949; Rafiq et al., 2016). The most abundant amino acid fermenters in the small intestine include genera from Clostridiales, Proteobacteria, and the Bacillus-LactobacillusStreptococcus group (Dai et al., 2011). While we didn't observe any substantial changes in these groups associated with animal origin, we did observe changes in Proteobacteria, Lactobacillus, and Streptococcus in the yogurts that may have been influenced by the availability of amino acids. The changes in lactic acid bacterial abundance are more likely due the difference in availability of casein between milk and yogurt. The lactic acid bacteria used in yogurt starter cultures can have casein-specific proteases which may break down casein during the fermentation process (Liu et al., 2010; Atanasova et al., 2014); this would leave less available to be delivered to the gut microbial community.

Bioactive compounds, such as peptides derived from proteolysis during fermentation, represent another mechanism by which bacterial communities can be influenced. Bioactive peptide composition and activity has been shown to differ between ruminants (e.g., cow, sheep, etc.) following in vitro digestion of milk (Tagliazucchi et al., 2018). Many bacterial starter and adjunct cultures used in yogurt manufacture are known to induce the release of bioactive peptides and bacterial strain influences which bioactive peptides are produced (Nguyen et al., 2015). In the parallel study, the number of different bioactive peptides present in milk increased with fermentation (Dalziel et al., 2018). Bioactive peptides from both whey and casein protein fractions of cow milk have been previously shown to stimulate the growth of Bifidobacterium and Lactobacillus (Azuma et al., 1984; Idota et al., 1994). Other milk peptides, such as lactoferrin, are known to have antimicrobial activity while their derivatives are capable of stimulating bifidobacteria growth (Liepke et al., 2002). The increased diversity and availability of these peptides following fermentation in our study, may have influenced the composition of the microbial community as some of the observed taxonomic changes are known to be influenced by bioactive peptides. In the parallel study, species origin affected total gut transit time (sheep faster than cow) while fermentation did not (milk and yogurt from same origin species were not different) (Dalziel et al., 2018). We did not note any correlations between bacterial abundance and transit time that appeared to be influenced specifically by origin species or fermentation status. A peptide analysis run in the parallel study, identified a $\beta$-casomorphin-7 peptide in both the cow milk and yogurt which may have contributed to slower transit (Dalziel et al., 2018).

Complex bacterial communities are not driven by simple direct substrate to strain-specific utilization dynamics, but rather complex interactions such as competition and crossfeeding that function more like a metabolic network (Fischbach and Sonnenburg, 2011). These types of microbial interactions may have driven observed changes in bacterial community composition in this study due to both origin species (composition of the milks) effects and fermentation. We currently lack an understanding of the outcomes of competition and cooperation for specific nutrients among gut microbial communities in their native environment, so it is difficult to predict the size and direction of their impact.

\section{CONCLUSION}

In summary, this study offers insights into the effects that fermented milk (yogurt) has on the gut microbiota as compared with unfermented milk in a healthy host. It also examined how the differences in animal origin of the milk (cow vs. sheep) might influence gut bacterial communities. We hypothesized, based partially on data from the parallel study, that animal origin would drive gut microbial composition to a greater extent than fermentation. However, while animal origin only impacted the abundance of a single genus (Collinsella), fermentation appeared to have a greater effect. The cow milk treatment was shown to produce changes in taxa and wider intra-treatment variation not observed in the other treatment groups. Of particular note, the abundance of Collinsella aerofaciens was much higher in the CM treatment than other groups. This may reflect a uniqueness in the availability of substrates and microbial interactions, including cross-feeding, that allowed it to flourish. Future studies looking at the effects of fermentation are needed to gain a greater understanding behind the microbial metabolic processes taking place by measuring bacterial metabolites and surveying microbial gene capability through shotgun metagenomics or RNA-Seq.

\section{DATA AVAILABILITY}

The sequencing data has been deposited into the NCBI SRA archive under Bioproject \# PRJNA473571.

\section{AUTHOR CONTRIBUTIONS}

JD designed the study. ER analyzed and interpreted the data and wrote the manuscript. ER, EA, NR, and JD were involved in manuscript discussion and revision and approved the final version.

\section{FUNDING}

This work was supported by the Strategic Science Investment Fund (contract \# A21246) and AgResearch SSIF Core Funding (A23127) from AgResearch, New Zealand. 


\section{ACKNOWLEDGMENTS}

We thank Blue River Dairy (Invercargill, New Zealand) for kindly providing the sheep skim milk powder and NZ Food Innovation (Waikato) Ltd. for the cow skim milk powder. We thank the following AgResearch staff: S. E. Burton for technical assistance, D. Robinson for animal care, R. Broadhurst and B. Smith for animal breeding, C. Berry and P. Harris for initial yogurt experiments to tailor fermentation scale-up, and M. Callaghan for microbiology. We thank Cilantro Cheese

\section{REFERENCES}

Adolfsson, O., Meydani, S. N., and Russell, R. M. (2004). Yogurt and gut function. Am. J. Clin. Nutr. 80, 245-256. doi: 10.1093/ajcn/80.2.245

Alm, L. (1982). Effect of fermentation on lactose, glucose, and galactose content in milk and suitability of fermented milk products for lactose intolerant individuals. J. Dairy Sci. 65, 346-352. doi: 10.3168/jds.S0022-0302(82)82198-X

Altschul, S. F., Gish, W., Miller, W., Myers, E. W., and Lipman, D. J. (1990). Basic local alignment search tool. J. Mol. Biol. 215, 403-410. doi: 10.1016/S00222836(05)80360-2

Atanasova, J., Moncheva, P., and Ivanova, I. (2014). Proteolytic and antimicrobial activity of lactic acid bacteria grown in goat milk. Biotechnol. Biotechnol. Equip. 28, 1073-1078. doi: 10.1080/13102818.2014.971487

Azcarate-Peril, M. A., Ritter, A. J., Savaiano, D., Monteagudo-Mera, A., Anderson, C., Magness, S. T., et al. (2017). Impact of short-chain galactooligosaccharides on the gut microbiome of lactose-intolerant individuals. Proc. Natl. Acad. Sci. U.S.A. 114, E367-E375. doi: 10.1073/ pnas. 1606722113

Azuma, N., Yamauchi, K., and Mitsuoka, T. (1984). Bifidus growth-promoting activity of a glycomacropeptide derived from human K-casein. Agric. Biol. Chem. 48, 2159-2162. doi: 10.1080/00021369.1984.10866469

Balthazar, C. F., Pimentel, T. C., Ferrão, L. L., Almada, C. N., Santillo, A., Albenzio, M., et al. (2017). Sheep milk: physicochemical characteristics and relevance for functional food development. Compr. Rev. Food Sci. Food Saf. 16, 247-262. doi: 10.1111/1541-4337.12250

Bokulich, N. A., Chung, J., Battaglia, T., Henderson, N., Jay, M., Li, H., et al. (2016). Antibiotics, birth mode, and diet shape microbiome maturation during early life. Sci. Trans. Med. 8:343ra382. doi: 10.1126/scitranslmed.aad7121

Cardoso Umbelino Cavallini, D., Jovenasso Manzoni, M., Bedani, R., Roselino, M., Celiberto, L., Vendramini, R., et al. (2016). Probiotic soy product supplemented with isoflavones improves the lipid profile of moderately hypercholesterolemic men: a randomized controlled trial. Nutrients 8:52. doi: 10.3390/nu80 10052

Chen, J., Wright, K., Davis, J. M., Jeraldo, P., Marietta, E. V., Murray, J., et al. (2016). An expansion of rare lineage intestinal microbes characterizes rheumatoid arthritis. Genome Med. 8:43. doi: 10.1186/s13073-016-0299-7

Chen, M., Sun, Q., Giovannucci, E., Mozaffarian, D., Manson, J. E., Willett, W. C., et al. (2014). Dairy consumption and risk of type 2 diabetes: 3 cohorts of US adults and an updated meta-analysis. BMC Med. 12:215. doi: 10.1186/s12916014-0215-1

Cho, I., and Blaser, M. J. (2012). The human microbiome: at the interface of health and disease. Nat. Rev. Genet. 13, 260-270. doi: 10.1038/nrg3182

Dai, Z. L., Wu, G., and Zhu, W. Y. (2011). Amino acid metabolism in intestinal bacteria: links between gut ecology and host health. Front. Biosci. 16, 1768-1786. doi: 10.2741/3820

Dalziel, J., Smolenski, G. A., McKenzie, C. M., Haines, S. R., and Day, L. (2018). Differential effects of sheep and cow skim milk before and after fermentation on gastrointestinal transit of solids in a rat model. J. Funct. Foods 47, 116-126. doi: 10.1016/j.jff.2018.05.039

Dalziel, J. E., Young, W., Bercik, P., Spencer, N. J., Ryan, L. J., Dunstan, K. E., et al. (2016). Tracking gastrointestinal transit of solids in aged rats as pharmacological models of chronic dysmotility. Neurogastroenterol. Motil. 28, 1241-1251. doi: $10.1111 / \mathrm{nmo} .12824$
Limited, Hamilton for fermenting the milks. We would also like to thank L. Day for helpful discussions and our reviewers for their input.

\section{SUPPLEMENTARY MATERIAL}

The Supplementary Material for this article can be found online at: https://www.frontiersin.org/articles/10.3389/fmicb. 2019.00458/full\#supplementary-material

David, L. A., Maurice, C. F., Carmody, R. N., Gootenberg, D. B., Button, J. E., Wolfe, B. E., et al. (2014). Diet rapidly and reproducibly alters the human gut microbiome. Nature 505, 559-563. doi: 10.1038/nature12820

Dewulf, E. M., Cani, P. D., Claus, S. P., Fuentes, S., Puylaert, P. G., Neyrinck, A. M., et al. (2013). Insight into the prebiotic concept: lessons from an exploratory, double blind intervention study with inulin-type fructans in obese women. Gut 62, 1112-1121. doi: 10.1136/gutjnl-2012303304

Díaz-López, A., Bulló, M., Martínez-González, M. A., Corella, D., Estruch, R., Fitó, M., et al. (2016). Dairy product consumption and risk of type 2 diabetes in an elderly Spanish Mediterranean population at high cardiovascular risk. Eur. J. Nutr. 55, 349-360. doi: 10.1007/s00394-015-0855-8

El-Agamy, E. I. (2007). The challenge of cow milk protein allergy. Small Rumin. Res. 68, 64-72. doi: 10.1016/j.smallrumres.2006.09.016

Elli, M., Callegari, M. L., Ferrari, S., Bessi, E., Cattivelli, D., Soldi, S., et al. (2006). Survival of yogurt bacteria in the human gut. Appl. Environ. Microbiol. 72, 5113-5117. doi: 10.1128/AEM.02950-05

Erdmann, K., Cheung, B. W. Y., and Schröder, H. (2008). The possible roles of food-derived bioactive peptides in reducing the risk of cardiovascular disease. J. Nutr. Biochem. 19, 643-654. doi: 10.1016/j.jnutbio.2007.11.010

Fekete, Á. A., Ian Givens, D., and Lovegrove, J. A. (2015). Casein-derived lactotripeptides reduce systolic and diastolic blood pressure in a metaanalysis of randomised clinical trials. Nutrients 7, 659-681. doi: 10.3390/nu701 0659

Fijan, S. (2014). Microorganisms with claimed probiotic properties: an overview of recent literature. Int. J. Environ. Res. Public Health 11, 4745-4767. doi: 10.3390/ijerph110504745

Filteau, M., Matamoros, S., Savard, P., and Roy, D. (2013). Molecular monitoring of fecal microbiota in healthy adults following probiotic yogurt intake. Pharmanutrition 1, 123-129. doi: 10.1016/j.phanu.2013.05.002

Fischbach, M. A., and Sonnenburg, J. L. (2011). Eating for two: how metabolism establishes interspecies interactions in the gut. Cell Host Microbe 10, 336-347. doi: 10.1016/j.chom.2011.10.002

Frank, D. N., Amand, A. L. S., Feldman, R. A., Boedeker, E. C., Harpaz, N., and Pace, N. R. (2007). Molecular-phylogenetic characterization of microbial community imbalances in human inflammatory bowel diseases. Proc. Natl. Acad. Sci. U.S.A. 104, 13780-13785. doi: 10.1073/pnas.0706625104

Gänzle, M. G., and Follador, R. (2012). Metabolism of oligosaccharides and starch in lactobacilli: a review. Front. Microbiol. 3:340. doi: 10.3389/fmicb.2012. 00340

Gibson, G. R., Cummings, J. H., and Macfarlane, G. T. (1991). Growth and activities of sulphate-reducing bacteria in gut contents of healthy subjects and patients with ulcerative colitis. FEMS Microbiol. Lett. 86, 103-111. doi: 10.1111/j.15746968.1991.tb04799.x

Gordon, W. G., Semmett, W. F., Cable, R. S., and Morris, M. (1949). Amino acid composition of $\alpha$-casein and $\beta$-casein2. J. Am. Chem. Soc. 71, 3293-3297. doi: 10.1021/ja01178a006

Guyonnet, D., Chassany, O., Ducrotte, P., Picard, C., Mouret, M., Mercier, C. H., et al. (2007). Effect of a fermented milk containing Bifidobacterium animalis DN-173 010 on the health-related quality of life and symptoms in irritable bowel syndrome in adults in primary care: a multicentre, randomized, doubleblind, controlled trial. Aliment. Pharmacol. Ther. 26, 475-486. doi: 10.1111/j. 1365-2036.2007.03362.x 
Hartmann, R., and Meisel, H. (2007). Food-derived peptides with biological activity: from research to food applications. Curr. Opin. Biotechnol. 18, 163-169. doi: 10.1016/j.copbio.2007.01.013

Hata, Y., Yamamoto, M., Ohni, M., Nakajima, K., Nakamura, Y., and Takano, T. (1996). A placebo-controlled study of the effect of sour milk on blood pressure in hypertensive subjects. Am. J. Clin. Nutr. 64, 767-771. doi: 10.1093/ajcn/64. 5.767

Ibrahim, S. A., and Carr, J. P. (2006). Viability of bifidobacteria in commercial yogurt products in North Carolina during refrigerated storage. Int. J. Dairy Technol. 59, 272-277. doi: 10.1111/j.1471-0307.2006.00282.x

Idota, T., Kawakami, H., and Nakajima, I. (1994). Growth-promoting effects of $\mathrm{N}$-acetylneuraminic acid-containing substances on bifidobacteria. Biosci. Biotechnol. Biochem. 58, 1720-1722. doi: 10.1271/bbb.58.1720

Joossens, M., Huys, G., Cnockaert, M., De Preter, V., Verbeke, K., Rutgeerts, P., et al. (2011). Dysbiosis of the faecal microbiota in patients with Crohn's disease and their unaffected relatives. Gut 60, 631-637. doi: 10.1136/gut.2010.223263

Kageyama, A., Benno, Y., and Nakase, T. (1999). Phylogenetic and phenotypic evidence for the transfer of Eubacterium aerofaciens to the genus Collinsella as Collinsella aerofaciens gen. nov., comb. nov. Int. J. Syst. Bacteriol. 49(Pt 2), 557-565. doi: 10.1099/00207713-49-2-557

Kawase, M., Hashimoto, H., Hosoda, M., Morita, H., and Hosono, A. (2000). Effect of administration of fermented milk containing whey protein concentrate to rats and healthy men on serum lipids and blood pressure. J. Dairy Sci. 83, 255-263. doi: 10.3168/jds.S0022-0302(00)74872-7

Kovatcheva-Datchary, P. (2010). Analyzing the Functionality of the Human Intestinal Microbiota by Stable Isotope Probing. Wageningen: Proefschrift Maken.

Laatikainen, R., Koskenpato, J., Hongisto, S. M., Loponen, J., Poussa, T., Hillilä, M., et al. (2016). Randomised clinical trial: low-FODMAP rye bread vs. regular rye bread to relieve the symptoms of irritable bowel syndrome. Aliment. Pharmacol. Ther. 44, 460-470. doi: 10.1111/apt.13726

Lambeth, S. M., Carson, T., Lowe, J., Ramaraj, T., Leff, J. W., Luo, L., et al. (2015). Composition, diversity and abundance of gut microbiome in prediabetes and type 2 diabetes. J. Diabetes Obes. 2, 1-7. doi: 10.15436/2376-0949.15.031

Lecomte, V., Kaakoush, N. O., Maloney, C. A., Raipuria, M., Huinao, K. D., Mitchell, H. M., et al. (2015). Changes in gut microbiota in rats fed a high fat diet correlate with obesity-associated metabolic parameters. PLoS One 10:e0126931. doi: 10.1371/journal.pone. 0126931

Ley, R. E., Bäckhed, F., Turnbaugh, P., Lozupone, C. A., Knight, R. D., and Gordon, J. I. (2005). Obesity alters gut microbial ecology. Proc. Natl. Acad. Sci. U.S.A. 102, 11070-11075. doi: 10.1073/pnas.0504978102

Ley, R. E., Turnbaugh, P. J., Klein, S., and Gordon, J. I. (2006). Human gut microbes associated with obesity. Nature 444, 1022-1023. doi: 10.1038/4441022a

Li, L., Su, Q., Xie, B., Duan, L., Zhao, W., Hu, D., et al. (2016). Gut microbes in correlation with mood: case study in a closed experimental human life support system. Neurogastroenterol. Motil. 28, 1233-1240. doi: 10.1111/nmo.12822

Liepke, C., Adermann, K., Raida, M., Magert, H. J., Forssmann, W. G., and Zucht, H. D. (2002). Human milk provides peptides highly stimulating the growth of bifidobacteria. Eur. J. Biochem. 269, 712-718. doi: 10.1046/j.0014-2956.2001. 02712.x

Liu, M., Bayjanov, J. R., Renckens, B., Nauta, A., and Siezen, R. J. (2010). The proteolytic system of lactic acid bacteria revisited: a genomic comparison. BMC Genomics 11:36. doi: 10.1186/1471-2164-11-36

Malinen, E., Krogius-Kurikka, L., Lyra, A., Nikkila, J., Jaaskelainen, A., Rinttila, T., et al. (2010). Association of symptoms with gastrointestinal microbiota in irritable bowel syndrome. World J. Gastroenterol. 16, 4532-4540. doi: 10.3748/ wjg.v16.i36.4532

Mater, D. D. G., Bretigny, L., Firmesse, O., Flores, M.-J., Mogenet, A., Bresson, J.-L., et al. (2005). Streptococcus thermophilus and Lactobacillus delbrueckii subsp. bulgaricus survive gastrointestinal transit of healthy volunteers consuming yogurt. FEMS Microbiol. Lett. 250, 185-187. doi: 10.1016/j.femsle.2005. 07.006

McNulty, N. P., Yatsunenko, T., Hsiao, A., Faith, J. J., Muegge, B. D., Goodman, A. L., et al. (2011). The impact of a consortium of fermented milk strains on the gut microbiome of gnotobiotic mice and monozygotic twins. Sci. Trans. Med. 3:106ra106. doi: 10.1126/scitranslmed.3002701

Nagata, S., Asahara, T., Wang, C., Suyama, Y., Chonan, O., Takano, K., et al. (2016). The effectiveness of lactobacillus beverages in controlling infections among the residents of an aged care facility: a randomized placebo-controlled double-blind trial. Ann. Nutr. Metab. 68, 51-59. doi: 10.1159/000442305

Nguyen, D. D., Johnson, S. K., Busetti, F., and Solah, V. A. (2015). Formation and degradation of beta-casomorphins in dairy processing. Crit. Rev. Food Sci. Nutr. 55, 1955-1967. doi: 10.1080/10408398.2012.740102

Oozeer, R., Leplingard, A., Mater, D. D. G., Mogenet, A., Michelin, R., Seksek, I., et al. (2006). Survival of Lactobacillus casei in the human digestive tract after consumption of fermented milk. Appl. Environ. Microbiol. 72, 5615-5617. doi: 10.1128/aem.00722-06

Ouwehand, A. C., and Salminen, S. J. (1998). The health effects of cultured milk products with viable and non-viable bacteria. Int. Dairy J. 8, 749-758. doi: 10.1016/S0958-6946(98)00114-9

Pessione, E., and Cirrincione, S. (2016). Bioactive molecules released in food by lactic acid bacteria: encrypted peptides and biogenic amines. Front. Microbiol. 7:876. doi: $10.3389 /$ fmicb.2016.00876

Price, M. N., Ray, J., Wetmore, K. M., Kuehl, J. V., Bauer, S., Deutschbauer, A. M., et al. (2014). The genetic basis of energy conservation in the sulfate-reducing bacterium Desulfovibrio alaskensis G20. Front. Microbiol. 5:577. doi: 10.3389/ fmicb.2014.00577

Quast, C., Pruesse, E., Yilmaz, P., Gerken, J., Schweer, T., Yarza, P., et al. (2013). The SILVA ribosomal RNA gene database project: improved data processing and web-based tools. Nucleic Acids Res. 41, D590-D596. doi: 10.1093/nar/gks 1219

Rafiq, S., Huma, N., Pasha, I., Sameen, A., Mukhtar, O., and Khan, M. I. (2016). Chemical composition, nitrogen fractions and amino acids profile of milk from different animal species. Asian Aust. J. Anim. Sci. 29, 1022-1028. doi: 10.5713/ ajas. 15.0452

Rajilić-Stojanović, M., and de Vos, W. M. (2014). The first 1000 cultured species of the human gastrointestinal microbiota. FEMS Microbiol. Rev. 38, 996-1047. doi: 10.1111/1574-6976.12075

Raveschot, C., Cudennec, B., Coutte, F., Flahaut, C., Fremont, M., Drider, D., et al. (2018). Production of bioactive peptides by Lactobacillus species: from gene to application. Front. Microbiol. 9:2354. doi: 10.3389/fmicb.2018.02354

Rognes, T., Flouri, T., Nichols, B., Quince, C., and Mahe, F. (2016). VSEARCH: a versatile open source tool for metagenomics. PeerJ 4:e2584. doi: 10.7717/peerj. 2584

Rooks, M. G., Veiga, P., Wardwell-Scott, L. H., Tickle, T., Segata, N., Michaud, M., et al. (2014). Gut microbiome composition and function in experimental colitis during active disease and treatment-induced remission. ISME J. 8, 1403-1417. doi: 10.1038/ismej.2014.3

Rowan, F., Docherty, N. G., Murphy, M., Murphy, B., Coffey, J. C., and O'Connell, P. R. (2010). Desulfovibrio bacterial species are increased in ulcerative colitis. Dis. Colon Rectum 53, 1530-1536. doi: 10.1007/DCR.0b013e3181f1e620

Savijoki, K., Ingmer, H., and Varmanen, P. (2006). Proteolytic systems of lactic acid bacteria. Appl. Microbiol. Biotechnol. 71, 394-406. doi: 10.1007/s00253006-0427-1

Schloss, P. D., Gevers, D., and Westcott, S. L. (2011). Reducing the effects of PCR amplification and sequencing artifacts on $16 \mathrm{~S}$ rRNA-based studies. PLoS One 6:e27310. doi: 10.1371/journal.pone.0027310

Schloss, P. D., Westcott, S. L., Ryabin, T., Hall, J. R., Hartmann, M., Hollister, E. B., et al. (2009). Introducing mothur: open-source, platform-independent, community-supported software for describing and comparing microbial communities. Appl. Environ. Microbiol. 75, 7537-7541. doi: 10.1128/AEM. 01541-09

Segata, N., Izard, J., Waldron, L., Gevers, D., Miropolsky, L., Garrett, W. S., et al. (2011). Metagenomic biomarker discovery and explanation. Genome Biol. 12:R60. doi: 10.1186/gb-2011-12-6-r60

Shin, N.-R., Whon, T. W., and Bae, J.-W. (2015). Proteobacteria: microbial signature of dysbiosis in gut microbiota. Trends Biotechnol. 33, 496-503. doi: 10.1016/j.tibtech.2015.06.011

Smid, E. J., Poolman, B., and Konings, W. N. (1991). Casein utilization by lactococci. Appl. Environ. Microbiol. 57, 2447-2452.

Spor, A., Koren, O., and Ley, R. (2011). Unravelling the effects of the environment and host genotype on the gut microbiome. Nat. Rev. Microbiol. 9, 279-290. doi: $10.1038 /$ nrmicro 2540

Tagliazucchi, D., Martini, S., Shamsia, S., Helal, A., and Conte, A. (2018). Biological activities and peptidomic profile of in vitro-digested cow, camel, goat and sheep milk. Int. Dairy J. 81, 19-27. doi: 10.1016/j.idairyj.2018.01.014 
Takahashi, K., Nishida, A., Fujimoto, T., Fujii, M., Shioya, M., Imaeda, H., et al. (2016). Reduced abundance of butyrate-producing bacteria species in the fecal microbial community in Crohn's disease. Digestion 93, 59-65. doi: 10.1159/ 000441768

Tannock, G. W., Munro, K., Bibiloni, R., Simon, M. A., Hargreaves, P., Gopal, P., et al. (2004). Impact of consumption of oligosaccharide-containing biscuits on the fecal microbiota of humans. Appl. Environ. Microbiol. 70, 2129-2136. doi: 10.1128/aem.70.4.2129-2136.2004

Turnbaugh, P. J., Hamady, M., Yatsunenko, T., Cantarel, B. L., Duncan, A., Ley, R. E., et al. (2009). A core gut microbiome in obese and lean twins. Nature 457, 480-484. doi: $10.1038 /$ nature 07540

Varhimo, E., Varmanen, P., Fallarero, A., Skogman, M., Pyörälä, S., Iivanainen, A., et al. (2011). Alpha- and $\beta$-casein components of host milk induce biofilm formation in the mastitis bacterium Streptococcus uberis. Vet. Microbiol. 149, 381-389. doi: 10.1016/j.vetmic.2010. 11.010

Veiga, P., Gallini, C. A., Beal, C., Michaud, M., Delaney, M. L., DuBois, A., et al. (2010). Bifidobacterium animalis subsp. lactis fermented milk product reduces inflammation by altering a niche for colitogenic microbes. Proc. Natl. Acad. Sci. U.S.A. 107, 18132-18137. doi: 10.1073/pnas.101173 7107

Veiga, P., Pons, N., Agrawal, A., Oozeer, R., Guyonnet, D., Brazeilles, R., et al. (2014). Changes of the human gut microbiome induced by a fermented milk product. Sci. Rep. 4:6328. doi: 10.1038/srep06328
Verna, E. C., and Lucak, S. (2010). Use of probiotics in gastrointestinal disorders: what to recommend? Therap. Adv. Gastroenterol. 3, 307-319. doi: 10.1177/ $1756283 \mathrm{X} 10373814$

Wallace, C. J. K., and Milev, R. (2017). The effects of probiotics on depressive symptoms in humans: a systematic review. Ann. Gen. Psychiatry 16:14. doi: 10.1186/s12991-017-0138-2

Wen, Y., He, Q., Ding, J., Wang, H., Hou, Q., Zheng, Y., et al. (2017). Cow, yak, and camel milk diets differentially modulated the systemic immunity and fecal microbiota of rats. Sci. Bull. 62, 405-414. doi: 10.1016/j.scib.2017.01.027

Zakrzewski, M., Proietti, C., Ellis, J. J., Hasan, S., Brion, M.-J., Berger, B., et al. (2017). Calypso: a user-friendly web-server for mining and visualizing microbiome-environment interactions. Bioinformatics 33, 782-783. doi: 10 . 1093/bioinformatics/btw725

Conflict of Interest Statement: The authors declare that the research was conducted in the absence of any commercial or financial relationships that could be construed as a potential conflict of interest.

Copyright (c) 2019 Rettedal, Altermann, Roy and Dalziel. This is an open-access article distributed under the terms of the Creative Commons Attribution License (CC BY). The use, distribution or reproduction in other forums is permitted, provided the original author(s) and the copyright owner(s) are credited and that the original publication in this journal is cited, in accordance with accepted academic practice. No use, distribution or reproduction is permitted which does not comply with these terms. 